Pensamiento Crítico Vol.17. N¹, pp. 09-18

\title{
Crisis y capitalismo: el riesgo implícito en la metamorfosis de la mercancía
}

\author{
Mag. Jorge Barrera Herrera ${ }^{1}$
}

\begin{abstract}
RESUMEN
En este artículo se revisan algunos aspectos poco analizados por investigadores y economistas, tienen que ver con las diferentes interrelaciones del capital, el valor y el trabajo en un entorno de constantes cambios tecnocientífico, de racionalización en el uso de los recursos naturales y su influencia sobre el proceso de transformación de la mercancía, desde que se produce hasta que se realiza su venta no garantizada, planteando algunos argumentos explicativos de cómo es que en una sociedad capitalista dependiente como la nuestra, se pueden y de hecho se están actualmente presentando ya en otras latitudes las crisis y de las cuales no estamos blindados.
\end{abstract}

Palabras claves: mercancía, trabajo concreto, trabajo abstracto, mercados, dinero, sistema de precios, sistema financiero especulativo, desregulación.

\section{ABSTRACT}

This article reviews some aspects little studied by researchers and economists who are concerned with the different inter-relations of capital, value and work in an environment of constantly changing techno-scientific, rational use of natural resources and their influence on the process of transformation of the goods from

1 Profesor asociado y miembro investigador del Instituto de Investigaciones de la Fac. Ciencias Económicas de UNMSM. Estudios de Doctorado en Economía UNMSM. Magíster en Administración UESAN. Licenciado en Ciencias Marítimas Navales ESNA. 


\section{Pensamiento Crítico Vol.I7. No I}

occurring until it makes its unsecured sale, raising some arguments explaining how it is that in a dependent capitalist society like ours, and in fact can be are currently presenting and crises elsewhere and which are not shielded.

Keywords: merchandise, concrete work, abstract labor, markets, money, price system, speculative financial system, deregulation.

\section{INTRODUCCIÓN}

El planteamiento de que todos los productos o mercancías ${ }^{2}$ tienen asegurada su venta futura cuando se fabrican, es un supuesto que generalmente se da por hecho $y$ que mistifica al mercado como un fórum que promueve siempre transacciones eficientes.

Ante la evidencia práctica del día a día, tenemos que admitir que este supuesto base que facilita muchos análisis microeconómicos no se cumple, es decir, siempre existirá la posibilidad e incertidumbre, para un tiempo futuro requerido, que los productos no sean realmente comprados o vendidos $y$, por tanto, se puedan convertir en dinero.

En las sociedades capitalistas, existe una sentencia ineludible que siempre se deberá cumplir: la venta de una mercancía solamente se realizará cuando el trabajo concreto $^{3}$ sea reconocido como trabajo abstracto ${ }^{4}$. En las sociedades capitalistas, las mercancías se intercambian en función de su valor de cambio y mediados por el valor, entender cómo es el proceso de la realización o distribución, comprender cómo se realiza la asignación de recursos dentro de un mercado es fundamental para comprender el desarrollo histórico de la sociedad capitalista.

En este artículo se exploran algunos aspectos poco revisados anteriormente para poder entender mejor la lógica mercantil del capitalismo en una economía dependiente como la peruana, cuyos factores tecnocientíficos su relación con el capital, el valor y el trabajo, en diferentes épocas la han sabido poner a prueba, sometiéndola a severas crisis

2 Es todo lo que se pueda comprar o vender, es decir que pueda ser intercambiable. Para el sistema de circulación en los mercados es importante destacar su capacidad de crear valor. Su característica común es su calidad de ser producto del trabajo humano.

3 Un tipo de categoría del trabajo. Cantidad de trabajo que efectivamente se ha utilizado para producir algo por el trabajador o productor específico, acreditado objetivamente.

4 Es la categoría del trabajo que articula la dimensión monetaria con la dimensión del trabajo. Es la cantidad de trabajo social que corresponde al precio monetario de un producto. Porción del trabajo social que el propietario de una mercancía puede reclamar para sí y que por lo tanto debe ser sancionada por el mercado. Magnitud monetaria del precio de la cantidad de trabajo social que se requiere para producir una mercancía. 


\section{Jorge Barrera Herrera}

y de la que siempre se ha podido reinventar para salir airosa; actualmente, además de ser la organización social más consensuada globalmente, está sometida a una más de esas pruebas.

La magnitud monetaria a la cual tienden los precios de mercado, llamada el precio natural ${ }^{5}$, está referido a alcanzar compensar el trabajo incurrido ${ }^{6}$ con el trabajo abstracto, esto se logra en el equilibrio con el reconocimiento social realizándose la venta, pero para lograr esto se tendrá que transitar por varias secuencias necesarias e inevitables.

La dinámica mercantil, en lo referente al proceso de transformación de la mercancía, implica reconocer la importante característica de la lógica secuencial en el horizonte temporal del proceso, debido a que hoy más que nunca, con tanta turbulencia y volatilidad en el entorno mercantil, tanto los productores como consumidores toman sus decisiones con un referente de tiempo delimitado, utilizando la información disponible del momento, y sus decisiones iniciales generan expectativas que no necesariamente son alcanzadas después, ello debido a ese secuencialismo lógico temporal al que está obligado a pasar la metamorfosis de la mercancía.

Los riesgos del mercado, por el proceso de transformación de la mercancía mencionado, es que no solo los precios esperados pueden no hacerse realidad sino que los productos no se lleguen a vender.

Para entender la necesaria transformación que debe sufrir la mercancía, cuya realización no está garantizada para cumplir a cabalidad su función como valor de cambio $^{7}$, podemos resumir el problema de la metamorfosis de la mercancía o "SALTO MORTAL" como lo llamó Carl Marx, de la siguiente manera:

"El valor de la mercancía, que se produce fundamentalmente para ser intercambiada, se formula en el momento de la producción y se sanciona en el momento de la venta o circulación (distribución, aceptación social, el mercado) y

5 Un tipo de categoría de precio. Magnitud monetaria hacia la cual tienden los precios de mercado por influencia de la competencia en la interacción de la circulación y producción.

6 Un tipo de categoría del trabajo que comprende la cantidad de trabajo que normalmente requiere utilizar la sociedad para producir algo en función de la tecnología disponible y la eficiencia corriente.

7 El ideal o la intención de la existencia de la mercancía es ser intercambiada, por tanto, existe la necesidad de ser realizada por el intercambio. 


\section{Pensamiento Crítico Vol.I7. No I}

su dimensión monetaria (valor dinerario, precio) es consustancial a que se realice y concrete su operación, dado que no existe la seguridad de su realización".

El productor tiene pleno control sobre su mercancía que produce pero está sometido al riesgo de no venderla o que alguien no la quiera comprar en el futuro, el rompimiento generalizado entre la producción y la realización genera las crisis capitalistas, algunas de las distintas razones son: anarquía de la producción, subconsumo de las masas, sobre acumulación del capital, la tendencia decreciente de la tasa de ganancia, la competencia, tiempo disponible, mercado incompleto, cambio de: tecnología, moda, preferencias, etc.

Este artículo explora algunas de las causas de la actual crisis, entendida esta como un mecanismo inherente al sistema para restablecer el necesario equilibrio perdido y además destacar que los capitalistas así como pueden disminuir sus tasas de ganancias para destruir a la competencia y lograr un mejor posicionamiento en los mercados también pueden autogenerar las crisis para golpear a la competencia y a los trabajadores cuyo poder, el sistema, tiende a disminuir, redistribuyendo la riqueza global en función de sus intereses.

Los productores establecen una relación social con los compradores o consumidores, a través de los mercados, pero la venta de la mercancía es espontánea y supuestamente no podría ser manejable ni controlable por ninguno de los actores, esta puede no efectuarse, costo que deberá asumir el productor y trabajador individual. En este artículo se revisan las nuevas tendencias que tratan de manipular e inducir las preferencias del consumo como alternativa para disminuir o eliminar el riesgo inherente de la realización en este proceso incierto por parte de los dueños de los medios de producción masivos.

En el CAPITALISMO, la forma de organizar las interrelaciones de sus miembros o agentes en los mercados, es fundamentalmente en EL MÓVIL DE LA GANANCIA EN BASE A LA COMPETENCIA por parte de los productores, y por la satisfacción de las NECESIDADES O PREFERENCIAS por parte de los consumidores o compradores.

Por tanto: "existe la incertidumbre de que las decisiones del productor individual no sean validadas por el mercado de manera idéntica a sus planes iniciales ocasionando pérdidas no deseadas". 


\section{Jorge Barrera Herrera}

La mercancía se produce para ser intercambiada en los mercados, teniendo esta un carácter dual, un valor de uso para el necesitado y valor de no uso para su productor o no necesitado, esta realidad genera una situación de inestabilidad para la mercancía que la dispara al que la necesita y la puede pagar, también llamado consumidor o comprador.

El proceso de transformación de la mercancía consiste en, como su nombre lo dice, convertir la mercancía (M) en dinero (D) para luego una vez convertida en dinero(M-D), volverse en otra mercancía (D-M) y así sucesivamente a través del proceso de circulación o intercambio en los mercados, de esta normalidad del proceso de transformación depende la estabilidad, desarrollo y continuidad de los mercados; sin embargo, este salto o disparo de la mercancía para su circulación, nunca está asegurado porque no hay garantía de que su transformación sea $100 \%$ exitosa, a pesar de incurrir en vitales costos laborales cuya implicancia social que de por sí generan exigencias colectivas especiales.

Para que la metamorfosis o disparo de la mercancía se efectivice a través de la circulación o venta, es necesario que el VALOR CONCRETO, es decir, el valor que para el productor representa el trabajo efectivamente utilizado para su fabricación (tasa salarial por las horas trabajadas), sea convalidado socialmente a través del mercado, esto debe significar, por tanto, que EL VALOR ABSTRACTO O SOCIAL que es el que comparte el poseedor del dinero o potencial comprador, debe coincidir con el VALOR INCORPORADO del trabajo social medio utilizado por el productor en su fabricación, coincidencia que sanciona y confirma SU NECESIDAD Y PREFERENCIA SOCIAL, y este a su vez debe coincidir con el VALOR CONCRETO. Esto disparará la mercancía y producirá su venta, atraerá para la circulación necesariamente el dinero expresado en un precio, generando liquidez, desarrollando y dando estabilidad al mercado, impulsando la economía y, por tanto, las oportunidades de ganancia capitalista.

Se debe destacar hasta aquí, que en el proceso mercantil capitalista descrito anteriormente, cualquier intercambio de mercancías efectiva entre los agentes se deberá realizar dentro de un mercado que posea a SISTEMA MONETARIO Y DE PRECIOS, lo que implica que las transacciones y comportamientos de los agentes se hacen con referencia al dinero.

\section{I3}




\section{Pensamiento Crítico Vol.17. No I}

Una de las principales razones de la división general del trabajo, es que a través de la calidad y productividad de su trabajo en la elaboración de un producto, mercancía o servicio, el hombre apuesta a su supervivencia física y espiritual. El trabajador, por tanto, se convierte en un especialista en un trabajo específico y competitivo, a sabiendas de que sus necesidades y preferencias son múltiples, motivo por el cual su producción (comúnmente no necesitado de ese producto) debe someterla necesariamente al intercambio, para convertirla en dinero y acceder a la adquisición de múltiples otras mercancías o poder satisfacer otras preferencias o necesidades. En el proceso de producción, el ¿qué?, ¿cuánto?, ¿cómo?, etc., fabricar, son procesos de toma de decisiones independientes de los productores, guiados por las señales del mercado, donde la competencia se rige por factores de escasez, oportunidades, preferencias, necesidades, amenazas, etc.

El valor es la medida de la importancia que concede el mercado, dentro de determinadas condiciones, a un producto, mercancía o servicio en la medida que este satisface necesidades o preferencias humanas o de los agentes. Se considera que el trabajo abstracto es la sustancia común e infaltable en toda mercancía o producto.

La magnitud del valor se expresa a través del precio, el cual se manifiesta a su vez dinerariamente.

\section{El capitalismo de hoy: su relación con la tecnología, el trabajo y el horizonte temporal para el comportamiento económico}

Muchas veces el uso de la tecnología, específicamente la informatización, la robotización, así como: la publicidad, la satisfacción de sus necesidades elementales de las grandes mayorías, han permitido crear, innovar, optimizar los procesos, producir y vender más, trayendo como lógica consecuencia asegurar su realización futura (la venta) y lograr reducir costos en la producción para obtener mayores ganancias; es decir, el trabajo concreto disminuye para luego después también disminuir el trabajo incurrido o incorporado. De esta manera, los trabajadores individuales, especialmente los dueños de los medios de producción, inmediatamente como consecuencia de su innovación en la producción obtienen como trabajo abstracto una cantidad que supera la cantidad de trabajo incorporada y que no consiguen sus competidores por no tener acceso a la tecnología innovadora. 


\section{Jorge Barrera Herrera}

Es necesario mencionar que la ganancia que obtienen los dueños de los medios de producción masiva por la utilización de nueva tecnología, en tanto que, no suele redistribuirse con sus trabajadores individuales asalariados y en el caso de que se produzcan pérdidas por los riesgos del "salto mortal", estas se prorrateará también entre sus trabajadores con mucha probabilidad.

Con la introducción en los procesos productivos de nueva tecnología, el trabajador en este período trabaja menos por unidad producida, y para que la masa de beneficio personal no disminuya deberá aumentar su productividad (dado que la existencia del diferencial del trabajo abstracto y del incurrido solo beneficia a los dueños de los medios de producción). En este período inicial de la innovación en la producción, los trabajadores individuales además de aumentar su productividad tienden a ser menos importantes en el proceso productivo, y a los requeridos se les demanda mayores capacidades y habilidades. Las condiciones salariales y laborales tienden a disminuir y ser poco flexibles, todo esto genera un aumento de la brecha en los niveles de ingresos, creando un conflicto de intereses e invitando a una mejor compensación y desprendimientos de las partes.

El diferencial o ganancia del trabajo abstracto y el tiempo que dure este, hasta que se produzca su compensación entre la cantidad de trabajo incurrida, dependerá de que la mercancía sujeta a innovación sea homogénea y mayoritaria (producción masiva) con relación a los productores de la competencia de la misma mercancía y en la velocidad que la competencia introduzca la nueva tecnología en sus procesos de producción, una vez ocurrido esto, aparecerá el precio natural, restableciendo la compensación e igualdad entre el trabajo abstracto y el trabajo incorporado, pero en un nivel bajo y poco atractivo para los inversionistas que buscan mayores ganancias.

\section{El cada vez más difícil alargamiento de los beneficios de la nueva tecnología}

Los dueños de los medios de producción en masa para alargar los beneficios de la nueva tecnología tratan de lograr que la sociedad plantee necesidades a los individuos, es decir, ya no son los hombres y sus necesidades los que proyectan una consecuente sociedad, sino todo lo contrario, es la sociedad que modela a los hombres induciéndoles necesidades con ayuda de la publicidad y la propaganda. 


\section{Pensamiento Crítico Vol.17. No I}

Cuando una sociedad tiene implementados sistemas de producción en masa, por acceder a nuevas tecnología y por haber logrado estandarizar e inducir las necesidades de la población con la ayuda de la publicidad, es posible también que la mayoría de su población, de esa misma sociedad, consiga lograr satisfacer plenamente sus necesidades básicas de alimentación, vestido, vivienda, luz, agua, etc., es en este escenario que la sociedad se vuelve conformista desincentivando la movilización social, que impulsa al individuo a poder alcanzar los medios para desarrollar y satisfacer necesidades superiores a la de los demás, en función de su trabajo y habilidad, desapareciendo el deseo de negatividad que implica la reivindicación autónoma de la existencia de la necesidad, según la propuesta de los marxistas.

En una sociedad conformista, como la descrita anteriormente, es mucho más fácil inducir en los ciudadanos las necesidades no elementales con ayuda de la publicidad, como dice André Gorz "si quiere ser reconocido por la sociedad, no puede ser como el mismo, sino como otro entre los otros, es la publicidad lo que le enseñará lo que debe ser y lo que son los demás".

Los dueños de los medios de producción en masa, en una sociedad donde la mayoría de la población consumidora tiene sus necesidades básicas satisfechas, para poder asegurar sus ventas futuras, asegurando sus mercados y ganancias sostenidas, debe lograr conseguir que las necesidades del público consumidor permanezcan siempre en crecimiento o sobre consumo, logrando que la gente no se fije de manera durable sobre un producto, creando necesidades de conformidad, prestigio y de lujo, que son necesidades sociales inducidas que se colocarán por encima de las reales necesidades autónomas, utilizando para ello la publicidad.

El acceso a la internet y las redes sociales hoy en día están logrando mediatizar la tradicional gran influencia de la publicidad sobre los consumidores, permitiendo el acceso a mayor información imparcial y desinteresada, fortaleciendo las exigencias de las necesidades autónomas de los consumidores, haciéndolos menos proclives a ser inducidos o manipulados. 


\section{Jorge Barrera Herrera}

\section{Comentarios finales}

Este proceso de producción cíclico y continuado, que dura cuando se inicia una innovación y termina cuando se alcanzan los precios naturales para luego continuar con la utilización de una nueva tecnología y así sucesivamente, está evolucionando hacia resultados poco rentables para los inversionistas en procesos de producción de la economía real frente a otras alternativas de inversión tales como las financieras, que evitan los riesgos ya mencionados de los procesos productivos y la realización de su producción en el llamado "salto mortal", evitan las fricciones laborales, además porque no es fácil descubrir e implementar nuevas tecnologías, también este crecimiento ilimitado de la producción y la productividad se enfrenta hoy en día más que ayer, a limitaciones de supervivencia de la humanidad y de conservación de recursos naturales y del medio ambiente global.

Está dinámica mercantil del capitalismo así como está yendo, ha convertido a la economía real en furgón de cola de la industria financiera, utilizando dinero ficticio, produciéndose una gigantesca transferencia masiva de capital del sector productivo al sector financiero especulativo, promovido por la desregulación, obteniendo mayores beneficios, más liquidez y menores tributos que pagar, predominando los procesos de financiamiento de la economía, que muestran cada vez más un sistema bancario global en banca rota que amenaza al sistema global del crédito para imponer una severa depresión en la económica real global.

En definitiva, son los valores, el perfeccionamiento institucional de las organizaciones, principalmente del Estado y su intervención, que con el uso de la razón y de la información disponible, se logre desalentar acciones de reinversión especulativa que no crea valor real, para conseguir finalmente disminuir el desempleo y alcanzar para el trabajador individual una relación justa entre lo que produce con su trabajo y lo que le es realmente pagado, en un ambiente de protección y conservación de la naturaleza.

\section{Bibliografía}

Jaramillo, Samuel (2009). Hacia una teoría de la renta del suelo urbano Segunda edición revisada y ampliada. Ediciones Uniandes. Bogotá. 


\section{Pensamiento Crítico Vol.17. No I}

André Gorz (1923/2007) Historia y enajenación. Textos selectos EUMEDNET.

Marx, Karl (1867/1975) El Capital: crítica a la economía política. Siglo XXI Editores. Buenos Aires (1862/1980) Teorías de la plusvalía. Fondo de Cultura Económica. México.

Ricardo, David (1817/1959) Principios de Economía Política y Tributación Fondo de Cultura Económica. México.

Smith, Adam (1776/1958). La riqueza de las naciones. Fondo de Cultura Económica. México-Buenos Aires. 